\title{
An Overview of Nigeria Information Policy
}

\author{
By \\ Abu Yusufu \\ Department of Library and Information Science, \\ Ahmadu Bello University, Zaria
}

\begin{abstract}
$\underline{\text { Abstract }}$
An information policy for Nigeria is most desirable in the face of the emergence of an information society. The purpose of this paper is to present a scenario of information activities in the various bodies responsible for information services especially in the public sector. The paper also believes that national policy on information can be traced amongst the various bodies involved with information production and distribution.
\end{abstract}

\section{Introduction}

Information is invaluable at all times and in all circumstances, especially to national development. The need to have a 'national policy' that will stimulate a cohesive information generation and dissemination environment has been discussed severally. Uhegbo, (2004); Alabi, (1994). Information policy is one of many different types of public policies that governments make. Nigeria is a very large country, socially and culturally diversified. It is the most populous country in Africa potentially a leading force in the international arena. Nigeria is endowed with an abundance of human and natural resources; it is in a continuum of socio-economic restructuring and adjustment. Civil rule and participatory politics; economic reforms; social reforms; educational reforms; science and technology drives; these are all areas of paramount importance for the future of the nation.

In the face of all these social and political uncertainties lies the dynamics of social cohesion. The role of information in the survival of Nigeria cannot be overemphasis.

\section{The Information Phenomenon}

Vickery, (1973:329) posits that information service has a social connotation in that it is responsible for the organizing, storing and dissemination of ideas. According to Shera (1976:44), it is impossible, that without the transmission of thought or information for the human civilization to have survived and achieved what it has today in terms of culture, language, speech, science and technology and social organisation. Her triangular expression as reproduced below remains a classic treatise on any discourse on information policy.

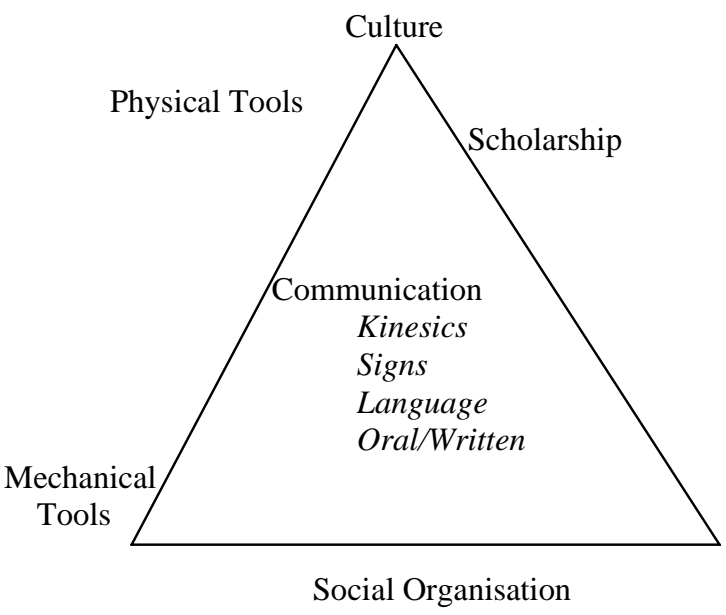

Kinetics and signs were earlier forms of information dissemination. The use of language which followed logically predated the written word. Graphics were some of the mechanical facet of communication. Today we are very much familiar with 'recording' and the impact of information communication technology (ICT) on information activities. Thus, it could be said that the development of civilization as we know it today is largely due to man's ability to exchange information and ideas.

\section{The Information Environment}

The information environment has a great impact on issues bordered on information policies. One way to capture the information environment is to consider how information activities takes place amongst individuals and institutions who are involved in the day-to-day processes of information creation, dissemination and use in the society. Information broadly represented can therefore be said to be any message to be conveyed from one source to another source or destination. Information created is embodied in different forms, which are 
represented as formats or channels of communication.

The forces that are shaping the information environment are the information components. These are: (i) information creating activities; (ii) information products; (iii) information distributors; (iv) information dissemination; and, (iv) information users. All these components can be referred to as stakeholders in information policy. The importance of information in our society can hardly be overestimated. As we increasingly recognize the critical nature of information, policies that affect information organisation, use, and dissemination become equally critical.

There are a variety of stakeholders in the information policy process, stakeholders who are deeply concerned about information from a legal or political perspective. Such stakeholders include:

(i) Business and industry - these are very active in influencing policies that will affect the dissemination of information and also are interested in both the discovery of new knowledge and the organisation of current knowledge.

(ii) Government ministries and parastatals which are responsible for information activities of government. These include:

(a) Federal Ministry of Information, Youth and Culture.

(b) Federal Ministry of Education.

(c) Federal Ministry of Science and Technology.

(d) Federal Ministry of Tourism.

(e) Federal Ministry of Transport and Aviation.

(f) Federal Ministry of National Planning.

(g) National Communication Commission.

(h) National Census Commission.

(i) Independent Electoral Commission.

These are only a few examples

\section{Information Policy}

Information policy is any law, regulation, rule, or practice (written or unwritten), that affects the creation, acquisition, organisation, dissemination, and/or evaluation of information. Most often, information policy is discussed in terms of governmental legislation. The goals of any policy may vary widely according to the organisation and in the context in which they are made. Broadly, policies are instituted in order to avoid some negative effect that has been noticed in the organisation, or to seek some positive benefit. Given the above scenario, the concept of policy is defined differently by different people. However a typical policy has the following attributes-a scope, a mechanism; an action. Each rule defines a scope initiating the policies; a framework or structure which embodies the mechanism of the policy implementation and the action which is the effects of the policy on national programmes and events.

\section{Information Policy Instrument in Nigeria}

Since the 1990s, efforts are being intensified for the formulation of information policy instruments by different bodies or stakeholders. Some of these efforts can be traced to:

(i) Mass media practitioners

(ii) Librarians/information scientists

(iii) Computer Association of Nigeria

(iv) Ministry of Science and Technology; and several other government ministries and parastatals.

The Ministry of Information, Youth and Culture, for example, has several parastatals and departments which are responsible for administering and implementing information policies. For examples, the Department of Culture is responsible for the formulation and execution of the national cultural policies for the promotion of all national cultural activities through the National Commission for Museums and Monuments and the Council for Arts and Culture. This body is responsible for the policies guiding national museums. The national museums contain artifacts that are of value to the historical heritage of our nation.

The National Library of Nigeria is a parastatal under the Ministry of Education. In its crusade for an information policy in Nigeria, the Nigerian Library association has organized several seminars, workshops, conferences with a view to coming out with a blue-print to enable the government formulate an information policy. For example, "Draft of the National Policy on Information Resources and Services" was produced at an NLA conferences held at ASCON, Topo, Badagry from February 18-20 1991. Amongst others, the 'draft' recommended as follows:

(i) All information must be available to all people, in all formats purveyed through all communication channels and delivered at all levels of comprehension.

(ii) All types of information resources and services produced in Nigeria constitute a vital investment in the national development efforts. Such information should be systematically collected, preserved and effectively managed as basic inputs to national development efforts at all levels.

(iii) Endogenous information and indigenous knowledge must be regularly integrated with externally generated information on Nigeria's development, as well as with relevant 
information on the development of other countries.

(iv) Nigeria's information resources and services must be organized in space and time so that waste is avoided or minimized. In particular, the acquisition, storage and sharing of information resources and services must be rationalized to ensure the optimal utilization of human, material and fiscal resources in national development.

(v) Information resources in all forms-oral, book, serial, print, electronic media, etc. must be harnessed and repackaged, using the most cost effective processing, communication and transport technologies available to deliver appropriately targeted information to all categories of Nigerians, and especially the illiterate and rural population who constitute more than $80 \%$ of the population.

Under the National Library, a National Information and Documentation Centre (NIDOC) was established as a bibliographic and numerical databank of information for the social and economic development of the country. And, as a focal point for the exchange of information, NIDOC intends to coordinate a network of participating centres in Nigeria. Alabi, (1994:19). Parts of its objectives are:

(i) Provision of active, dynamic information services, information retrieval, current awareness and information analysis/consolidation regarding published knowledge in harmony with the priorities of Nigerian research and technological development.

(ii) Provision of referral services with a view to making best use of the information resources in the country and abroad.

NIDOC is envisaged as a pivot information centre for the dissemination of intellectual information resources in formats such as database, indexing and abstracting services.

\section{Databank Activities in Nigeria}

Databank activity is the totality of computerized information technology. It includes the whole sphere of automated processing and technological utilization of information. One of the major aspects in electronic information is the development of databanks in various sectors. The focus of these databanks is to meet the demands and expectations of users of the vast amount of data for scientific, technological and socio-economic development. In recognition of this role, many organizations throughout the country are now training their personnel in the area of computer applications and appreciation.
A National Data Bank (NDB) has been established under the Federal Ministry of National Planning; which is now incorporated with the National Planning Commission. The activities of NDB commenced in February 1989. Decree No.12 of 1992 had further spelt out the functions and objectives of the NDB. With that instrument, the NDB is the apex data bank in Nigeria. It has a coordinating role in harnessing databases emanating from other parastatals of government.

\section{Science and Technology Information Policy} It has been established that one of the factors contributing to rapid industrialisation is the dissemination of usable research findings to industrialists in the language and format they understand. It is assumed therefore that inadequate or ineffective dissemination and use of information must have been responsible for the slow pace of industrial development in Nigeria. The National Science and Technology Policy intended to address this issue though the Raw Material Research and Development Council. (Abdullahi and Ajoku), The Council has embarked on a number of projects including the Raw Material Information System (RMIS). The RMIS has the mandate to provide a computerized information subsystem and an automated library that will enable investors and entrepreneurs obtain required information for developmental purposes. A National Science and Technology Databank have also been established to provide further information services in this respect. Ayo, (2000:223)

National frameworks for the implementation of science and technology information policy include:

(i) Increasing public awareness in science and technology and vital role in national development and well-being.

(ii) Directing science and technology efforts along identified national goals;

(iii) Promoting the translation of science and technology results into actual goods and services

(iv) Creating, increasing and maintaining an indigenous science and technology base through research and development;

(v) Motivating creative output in science and technology;

(vi) Increasing and strengthening the technological base of the nation.

\section{Information Activities of the Nigerian Universities}

The National Documentation and Information Centre for Science and Technology (NADICEST) initiative was also established in 1988 in the quest to promoting information activities amongst higher institutions of learning in the country. Ike (1992). Management Information System (MIS) was 
formally introduced into Nigerian universities management systems in 1990 under the supervisory role of the National Universities Commission (NUC). Sama'ila (1996:23). The ultimate objective of the project is to create a general awareness for accepting information technology in the teaching and research activities of the universities. Today this idea has culminated into the proliferation of computerization in the processing of information and provision of information services in our universities. Each university was encouraged to set up its own MIS Committee which will be responsible for implementation of information policies in respect of the MIS.

\section{National Communication Commission}

Policies and regulations aimed at the development of communication facilities can be referred to as 'telecommunications' policies. With the establishments of the Nigerian Communication Commission (NCC) in 1992, the telecommunication industries in Nigeria have now been completely privatized to improve information services. The Integrated Service Digital Network (ISDN) has provided the enabling facilities for the compatibility of both the analogue and the digital communication services effectively. These services include electronic mail, teleconferencing, fax messages and the short service messages. The Nigerian telecommunication environment has recently appreciated in its penetration of telephone lines per population density.

National Communication Policy of 1987 thus provided the mechanism for the inclusive mobilization of all the structures of human interaction, information exchanges and sharing of live experiences in the society. The major focus is the propagation of national goals. However, according to Alabi (1994) the objective, scope and coverage of its information content are being noticed only in the narrow areas of information dissemination.

\section{Conclusion}

Information policies can be identified in the various bodies responsible for information services both in the private and public sector. It should also be appreciated that though a single white paper on 'national information policy' do not yet exist; it is however business as usual for most information industries and stakeholders. In the main, a single information policy for the country should be able to address five basic cornerstones of information activities. These are:

(i) Free access to information.

(ii) Information Security.

(iii) Information storage and retrieval.

(iv) Information dissemination especially to rural areas and the less privileged.. (v) Information distribution.

Reference

Abdullahi, Ado K and Ajoku, Kemjika B. (1998). Raw Materials Information Network for Africa: a New Agenda for Development. Abuja, RMRDC. 271pp.

Aiyepeku, W. Olabode (1991). Towards a National Information and Informatics Policy. Paper presented at a Seminar on Libraries and Information Services for National Development, Lagos, 11-19 Sep. 29p.

Alabi, G.A. (2003) Case Study Effectiveness of Informatics Policy Instruments in Africa: Nigeria. African Information Society Initiative-ICT Policy. (downloaded, 2/4/2007) 54p.

Ayo, Daniel B. (2000). "Development and Management of National Research and Development Information Centre”. In: Ajayi, G. Olalere (ed). National Information Communication Infrastructure, Policy, Plan and Strategy, proceedings of a Workshop organized by Cooperative Information Network (C0PINE), pp223-245.

Ike, Adebimpe Olurunsola (ed) (1992). "Access to Science and Technology in Nigeria." Proceedings of the Workshop for Users and Disseminators of Science and Technology and Social Science Information (STSSI), Bauchi, NADICEST. 186pp.

The Institute for Cultural Democracy, Culturelink (1998). Cultural Policy in Nigeria. 8pp (http://www.wwcd.org/policy/clink/Nigeria.ht ml ) Downloaded 2/4/2007.

National Library of Nigeria (1991). National Policy on Information Resources and Services Proceedings Seminar on Libraries and Information Services for National Development, Lagos, 11-19 Sept.

Rubin, Richard E (2000). Foundations of Library and Information Services. New York, Neal Schuman Publishers, pp93-170.

Sama'ila, L.W (1996). "State of Affairs: MIS Operation Update.” $\underline{\text { In }}$ Actualising Management Information System (MIS) Operation in Nigerian Universities. Reports of 1995 StructuralSeminar... pp23-27.

Shera, Jesse H. (1996). Introduction to Library Science. Littleton, Colo.: pp.42-50. 
Uhegbu, Augonus Nnamdi (2004). “Constraints on the Formulation and Implementation of National Information Policy for Nigeria”. Journal of Information Science 31(1):41-47.

Vickery, B.C. (1973). Information System. London, Butterworths, pp.329.

Wikipeia, the free encyclopedia.htm (down loaded 8/4/2007). 